\title{
VII.
}

Aus einem Briefe des Herrn Commiffsonsrath $\mathrm{Bu}$ fle in Freiberg.

Ongleich in meiner Erinnerung gegen eine neue Formel über die oberjchlügigen Räder, Annalez 1808. B. 3. S. $415 .$, ftatt des $F$ meines Manufcripts jedes Mahl $I$ gedruckt, alfo die Denomination mit fich felbft übereinftimmend geblieben ift: fo wünfche ich doch meinen Lefern angezeigt zu fehen, dafs ich nicht 1 , fondern $F$, bier gebraucht hatte. Nothwendig aber ilt es ihnen, zu wilfen, daís clort zwei Mahl, S. 419. und 4zo., y ftatt $z u$ gedruckt fteht.

Gegen des Herrn Prechtl Etwas über die Bemerkungen etc., Annalen 1808 . St. 11. No. IV., hätte ich wohl einiges zu erinnern; aber ungleich lieber ift es mir im Ganzen genommen, verfichern zu können, dafs ich mich fehr freue, in Herrn Prechtl immer mehr und mehr einen Phyliker kennen zu lernen, von deffen Scharffinn und guten mathematifchen Kenntniffen wir noch viel Ruhmwürdiges ferner hin zu erwarten haben.

In die Sprengung mit Sandbefetzung nich zu mifchen, habe ich, das nächfte Jahr hindurch wenigftens, wegen vieler anderer Arbeiten, keine Zeit übrig; obgleich ich vermuthe, dals von Allen 


\section{[ 260$]$}

eine gewiffe Fauptfache nicht gehörig wird beurtheilt werden, da fie bisher, meines Wiffens, noch in keinem phyfikalifchen Lehrbuche richtig erklärt ift. Vor etwa 20 Jahren fchon babe ich eine Abhandlung darüber niedergefchrieben. Aber was von meinem niedergefchriebenen nicht fogleich gedruckt wird, das hat gute Ruhe, und wird nach meinem Tode (diefe Abhandlung indeffen ausgenommen) (chwerlich fur irgend jemand lesbar feyn. 